Matthijs Oyaert, Marijn M. Speeckaert and Joris R. Delanghe*

\title{
Estimated urinary osmolality based on combined urinalysis parameters: a critical evaluation
}

https://doi.org/10.1515/cclm-2018-1307

Received December 7, 2018; accepted January 21, 2019

\section{Abstract}

Background: Urinary conductivity allows a coarse prediction of urinary osmolality in most cases but is insensitive to the osmolal contribution of uncharged particles and the presence of roentgen contrast media. Urinary osmolality can be estimated on the recently introduced Sysmex UF-5000 urine analyzer using conductivity. In this study, we evaluated the analytical performance of this research parameter. Secondly, we aimed to improve the manufacturer's algorithm for estimating urinary osmolality, based on standard urinalysis parameters (creatinine, glucose, relative density). Methods: The analytical performance was determined and a prediction model to estimate urinary osmolality based on urinalysis parameters was developed. We further developed and validated a prediction model using another set of routine urine samples. In addition, the influence of roentgen contrast media on urinary osmolality was studied.

Results: The within-run and between imprecision for osmolality and conductivity measured on the Sysmex UF-5000 ranged from $1.1 \%$ to $4.9 \%$ and $0.7 \%$ to $4.8 \%$, respectively. Multiple regression analysis revealed urinary creatinine, conductivity and relative density to be the strongest predictors to estimate urinary osmolality. A mean difference of $1.3 \mathrm{mOsm} / \mathrm{kg}$ between measured and predicted osmolality demonstrated that the predictive performance of our model was favorable. An excellent correlation between the relative density and \% contrast media was demonstrated.

Conclusions: Urinary osmolality is an important parameter for assessing specimen dilution in urinalysis. Urinary conductivity, along with relative density and

*Corresponding author: Joris R. Delanghe, MD, PhD, Department of Clinical Chemistry, Ghent University, C. Heymanslaan 10, 9000 Ghent, Belgium; and Department of Laboratory Medicine, University Hospital Ghent, Ghent, Belgium, Phone: 09/332 29 56,

Fax: 09/332 49 85, E-mail: Joris.delanghe@ugent.be

Matthijs Oyaert: Department of Laboratory Medicine, University Hospital Ghent, Ghent, Belgium

Marijn M. Speeckaert: Department of Internal Medicine, University Hospital Ghent, Ghent, Belgium urinary creatinine allows a coarse prediction of urinary osmolality and is insensitive to the osmolal contribution of uncharged particles and the presence of roentgen contrast media.

Keywords: conductivity; contrast media; creatinine; glucose; relative density; urine osmolality.

\section{Introduction}

As hydration is a major pre-analytical confounder in urinalysis, a number of reference parameters have been introduced to assess urine dilution and hydration. Moreover, when assessing dysmorphic red blood cells (RBCs), morphological changes of RBCs are partly affected by osmotic changes [1]. The most commonly used reference analytes to assess sample dilution are relative density, urinary creatinine, conductivity and osmolality [2-6].

In urinalysis, dilution parameters are used to correct test results for dilution effects [7-10] and to interpret urinalysis findings regardless of the sample dilution. As reproducibility of modern urine analyzers is much lower than the reproducibility of classical microscopy-based urinalysis, the effects of pre-analytical variables (e.g. dilution) on test results has become increasingly important [11].

The parameter that is used as the gold standard to measure diuresis is osmolality [12]. It assists in the interpretation of other tests performed on the same urine specimen. However, osmolality determinations depend on the freezing-point depression method, which is a rather time-consuming technique which makes this parameter less suited for high throughput determinations in a routine clinical laboratory. Moreover, this technique for estimating urinary concentration is not readily available to many physicians.

Relative volume mass (relative density) is a commonly used alternative parameter. Relative density can be measured directly (by gravimetry) or indirectly by using test strips or by measuring the refractive index using a refractometer. The refractive index is related to the total mass of solutes present in a urine specimen. High relative density values are observed in the presence of iodine containing contrast media [7, 8].

According to Kohlrausch's law, electrical conductivity of dilute solutions depends on the concentration of all the 
charged particles present in the solution. As this approach is only sensitive for charged particles, the method is insensitive to uncharged particles such as glucose, urea and roentgen contrast media [8]. In contrast to osmometers, both refractometers and conductivity meters can be integrated into modern urine analyzers and therefore have gained popularity.

Due to its constant production rate, urinary creatinine concentration is also used as a marker for diuresis [4]. However, urinary creatinine output partly depends on muscle mass [9] and is therefore not useful as a urine dilution parameter in the case of sarcopenia. In some modern urine test strip analyzers, creatinine has become available [11].

New technological evolutions have become available in urinalysis and have led to alternative diagnostic approaches of urinary pathologies. Recently, the Sysmex UF-5000 automated urine sediment analyzer was introduced. This instrument is a third-generation fluorescence flow cytometry analyzer which makes an accurate count and differentiation of a broad variety of urinary cells possible [13]. In addition, urine osmolality has been introduced as a novel parameter in this instrument. In the present study, we aimed to assess the value of the estimated osmolality in urinalysis interpretation. Furthermore, we wanted to optimize algorithms for estimating urinary osmolality by including additional analytes in the estimation formula. Special attention has been paid to analytical interferences caused by the presence of roentgen contrast media on urinary dilution parameters.

\section{Materials and methods}

\section{Samples}

One hundred and two freshly collected routine urine samples originating from hospitalized patients at the University Hospital Ghent were included in this study. Besides urinary osmolality, the relative density (designated as specific gravity), creatinine, sodium, urea and glucose were also determined. Samples with a supraphysiological relative density $\left(>1.035 \mathrm{~kg} / \mathrm{dm}^{3}\right)$ were considered as analytical interferences (due to iodine containing contrast media) and were excluded from the study [7]. Pyuria (cut-off $=25 \mathrm{WBCs} / \mu \mathrm{L}$ ), hematuria (cutoff $=25 \mathrm{RBCs} / \mu \mathrm{L}$ ) and proteinuria (reference range: $0.0-0.2 \mathrm{~g} / \mathrm{L}$ ) was measured in $19.6 \%$ (20/102), 26.5\% (27/102) and 44.1\% (57/102), respectively, of the samples included in the correlation study. The median $\mathrm{pH}$ of these sample was 6.0 and ranged from 5.0 to 9.0. For testing the effects of glucosuria on osmolality, another group of 26 additional urine samples showing pronounced glucosuria $(>0.83 \mathrm{mmol} / \mathrm{L})$ were selected. The study was performed with full respect for individuals' rights to confidentiality and in accordance with procedures supervised by Local authorities responsible for Ethical Research.

\section{Methods}

Osmolality was measured by freezing-point depression method using an Osmostation OM-6050 automatic osmometer (Arkray, Amstelveen, The Netherlands) and estimated based on the electrical conductivity on the Sysmex UF-5000 urine sediment analyzer (Sysmex, Kobe, Japan). The Sysmex UF-5000 is a third-generation urinary flow cytometer-based analyzer that performs automated microscopic analysis. The UF-5000 is able to recognize count and classify cells by analyzing forward scatter light, side scatter light, side fluorescent light and the depolarized side scattered light of stained particles. Depolarized side scattered light was introduced to improve the sensitivity of crystals and to better discriminate the RBCs and crystals [13]. The principle is based on a $488 \mathrm{~nm}$ blue laser flow cytometry. The UF-5000 measures urinary conductivity and categorizes the particles based on their size, intracellular structure and staining characteristics. The signals are displayed in scattergrams, histograms, and the results are given as counts per $\mu \mathrm{L}$ as well as counts per high power field. The UF-5000 automatically detects and counts RBCs, non-lysed RBCs, white blood cells (WBC), WBC clumps, bacteria, yeast-like cells, crystals, different types of epithelial cells, like transitional or renal tubular cells, sperm cells and casts (hyaline and pathological). Urinary particles that cannot be classified in one of the former categories are counted as "other cells".

Creatinine was determined using quantitative urine test strip analysis on the automated Sysmex test strip reader UC-3500 (Meditape UC-11A, Sysmex, Kobe, Japan; Lot number: AC5004; Sysmex, Kobe, Japan) [11]. These strips include reagent pads for ordinal scale reporting of $\mathrm{pH}$, relative density, leukocyte esterase, hemoglobin peroxidase, nitrite, protein, glucose, ketones, urobilinogen, bilirubin, albumin and creatinine. The intensity of the reaction color of the test pad is detected by measuring the amount of light reflected from the surface of the test pad. The reflectance value, as a percentage within a range from $100 \%$ (white) to $0 \%$ (black), is inversely related to the concentration of the analyte [14]. Refractometry-based relative density and clarity are measured by the instrument. In this study, we used quantitative reflectance readings for statistical analysis [14]. Urinary sodium (indirect potentiometry), glucose (hexokinase method) and urea (colorimetric urease-based method) concentrations were determined on a Roche cobas 8000 c701 analyzer (Roche Diagnostics, Mannheim, Germany).

\section{Contrast media}

The effect of iodine containing radiographic contrast media was assessed by serial dilutions ( $0 \%-50 \%)$ of the contrast agent Iomeprol (300 g/L; 500 mOsm/kg) (Iomeron 300; Bracco Imaging, Konstanz, Germany) [15] in pooled urine samples with a baseline osmolality of $1279 \mathrm{mOsm} / \mathrm{kg}$. Consecutively, electrical conductivity, relative density and osmolality (measured and estimated) were measured in the mixed specimen. The theoretical osmolality of the mixture was based on the molecular mass of iomeprol $(777 \mathrm{~g} / \mathrm{mol})$. 


\section{Glucose effects}

Effects of glucosuria on the various urinary osmolality, conductivity and relative density was assessed by serially diluting a urine specimen containing $0.273 \mathrm{~mol} / \mathrm{L}$ of glucose originating from a patient daily treated with $25 \mathrm{mg}$ of empagliflozine.

\section{Statistical analysis}

Imprecision of the estimated osmolality and conductivity on the UF-5000 was assessed on commercial control materials (Bio-Rad Urine chemistry, LOT 68530, EXP: 03/2020) as well as on patient samples. Twenty aliquots of three levels with a low, medium and high osmolality were measured. Intra-run and between-run imprecision were determined in one run during 1 day and on 20 consecutive days with one analysis per day, respectively. The limit of quantification (LOQ) was determined by constructing a serial dilution curve of a urine sample with an estimated osmolality of $219 \mathrm{mOsm} / \mathrm{kg}$. The lowest concentration at which the coefficient of variation (CV) was lower than $20 \%$ was set as the LOQ [16].

Statistical analysis was performed using Medcalc software (version 15.6.1., Mariakerke, Belgium). A p-value of $<0.05$ was considered significant. The effects of potential confounders on urinary osmolality were assessed using a multiple regression model, only parameters that can be measured on the Sysmex UC-3500 and UF-5000 were included in the analysis.

The performance of the prediction model was assessed to determine the validity of the predicted osmolality (based on left-over samples). The study cohort for validation of the formula consisted of another 36 patient samples. Mean differences were calculated as the absolute difference between the measured and predicted osmolality (=osmolality predicted by the formula deduced from the multiple regression analysis).

\section{Results}

\section{Analytical performance}

The within-run and between-run imprecision for osmolality ranged from $1.1 \%$ to $2.0 \%$ and $1.2 \%$ to $4.9 \%$ for both patient and QC samples, respectively. For conductivity, the within-run and between-run imprecision ranged from $0.7 \%$ to $1.9 \%$ and $0.8 \%$ to $4.8 \%$ for both patient and QC samples, respectively. A summary of the imprecision results is presented in Table 1.

The LOQ for estimated osmolality and conductivity was determined by constructing a serial dilution curve. The lowest concentration at which the CV was lower than $20 \%$ for osmolality and conductivity was found to be $28.2 \mathrm{mOsm} / \mathrm{kg}$ (reference interval: 300-900 mOsm $/ \mathrm{kg}$ ) and $1.6 \mathrm{mS} / \mathrm{cm}$ (reference interval: $8-32 \mathrm{mS} / \mathrm{cm}$ ), respectively [17].

\section{Correlation study}

The median glucose, sodium and urea concentrations and osmolality of urine samples included in the correlation study were $0.28 \mathrm{mmol} / \mathrm{L}(0.00-153 \mathrm{mmol} / \mathrm{L})$, 97.0 (9.0-253.0 mmol/L) and $190 \mathrm{mmol} / \mathrm{L}$ (range: 0.00$497 \mathrm{mmol} / \mathrm{L}$ ), $500 \mathrm{mOsm} / \mathrm{kg}$ (range: 117-999 mOsm/kg), respectively.

Table 1: Imprecision results (patient and QC samples) of osmolality and conductivity on the Sysmex UF-5000 analyzer.

\begin{tabular}{|c|c|c|c|c|c|c|}
\hline & \multicolumn{3}{|c|}{ Osmolality } & \multicolumn{3}{|c|}{ Conductivity } \\
\hline & Mean, mOsm/kg & SD, m0sm/kg & $\mathrm{CV}, \%$ & Mean, $\mathrm{mS} / \mathrm{cm}$ & $\mathrm{SD}, \mathrm{mS} / \mathrm{cm}$ & CV, \% \\
\hline \multicolumn{7}{|l|}{ QC material } \\
\hline \multicolumn{7}{|c|}{ Within-run, $n=10$} \\
\hline Level 1 & 232.3 & 4.6 & 2.0 & 13.1 & 0.2 & 1.8 \\
\hline Level 2 & 415.1 & 5.2 & 1.3 & 22.6 & 0.2 & 1.1 \\
\hline \multicolumn{7}{|c|}{ Between-run $(n=20)$} \\
\hline Level 1 & 235.5 & 7.4 & 3.2 & 13.2 & 0.4 & 3.0 \\
\hline Level 2 & 416.3 & 6.5 & 1.6 & 22.6 & 0.3 & 1.5 \\
\hline \multicolumn{7}{|c|}{ Patient samples } \\
\hline \multicolumn{7}{|c|}{ Within-run $(n=10)$} \\
\hline Low & 150.3 & 3.0 & 2.0 & 8.6 & 0.2 & 1.9 \\
\hline Medium & 473.0 & 8.1 & 1.7 & 25.4 & 0.2 & 0.7 \\
\hline High & 578.4 & 6.3 & 1.1 & 30.5 & 0.4 & 1.3 \\
\hline \multicolumn{7}{|c|}{ Between-run $(n=20)$} \\
\hline Low & 147.0 & 7.2 & 4.9 & 8.4 & 0.4 & 4.8 \\
\hline Medium & 471.2 & 6.1 & 1.3 & 25.4 & 0.3 & 1.2 \\
\hline High & 579.9 & 6.7 & 1.2 & 30.6 & 0.3 & 0.8 \\
\hline
\end{tabular}

SD, standard deviation; CV, coefficient of variation. 


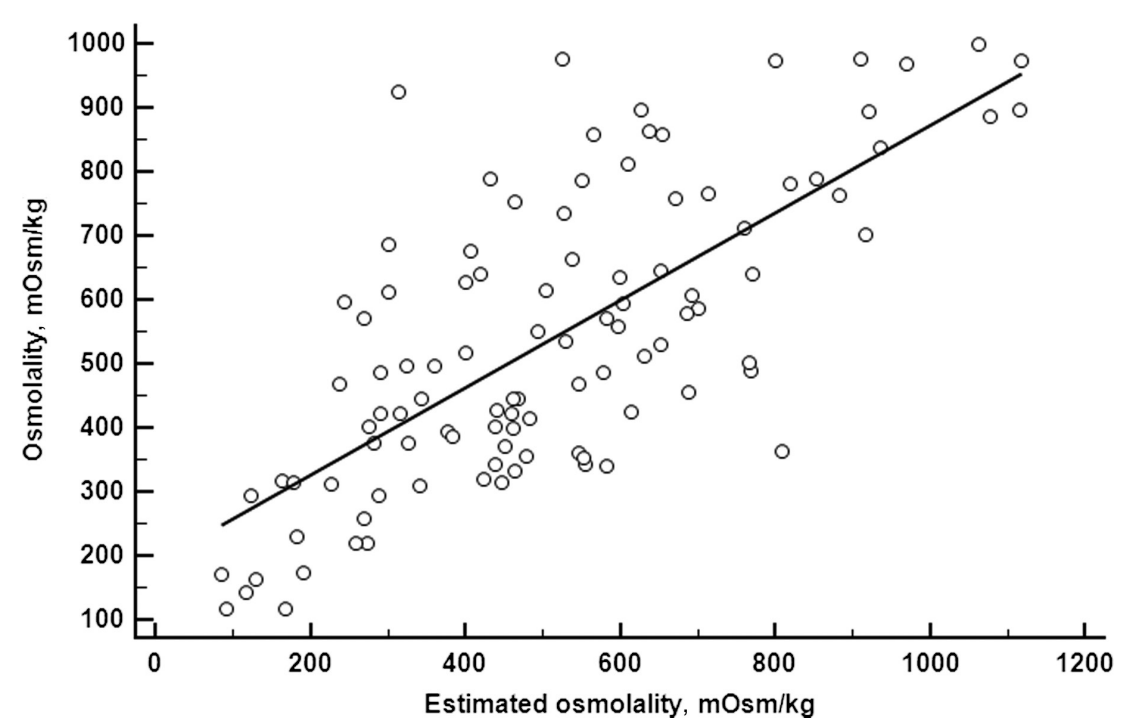

Figure 1: Correlation between the estimated (UF-5000) and measured (OM-6050) urinary osmolality. $\mathrm{y}($ measured osmolality; $\mathrm{mOsm} / \mathrm{kg})=0.695 \times($ estimated osmolality $[\mathrm{mOsm} / \mathrm{kg}])+180.16 ;\left(\mathrm{r}^{2}=0.539\right)$.

The following correlation between conductivity and measured osmolality was obtained: y (measured urinary osmolality; $\mathrm{mOsm} / \mathrm{kg})=23.83 \times$ (urinary conductivity, $\mu \mathrm{S} / \mathrm{cm})+181.25\left(\mathrm{r}^{2}=0.539\right)$. In Figure 1 , the correlation between the measured and estimated osmolality is presented: y (measured osmolality; $\mathrm{mOsm} / \mathrm{kg})=0.695 \times($ estimated osmolality $[\mathrm{mOsm} / \mathrm{kg}])+180.16\left(\mathrm{r}^{2}=0.539\right)$. In this approach (used by the manufacturer), the unexplained variance is mainly due to the urinary urea concentration.
Adding urinary urea concentration to the model increased the determination coefficient $\left(\mathrm{r}^{2}\right)$ to 0.909 . As data on urea concentration are not available on the urinary test strip, we searched for additional dilution parameters showing a good correlation with urinary urea concentration.

The correlation between the inverse reflectance data of the creatinine pad and the urinary urea concentration was: $\mathrm{y}(1 /$ reflectance creatinine $[\%])=0.04162 \times($ urea concentration, mol/L) $+0.01819(\mathrm{r}=0.721) \quad$ (Figure 2).

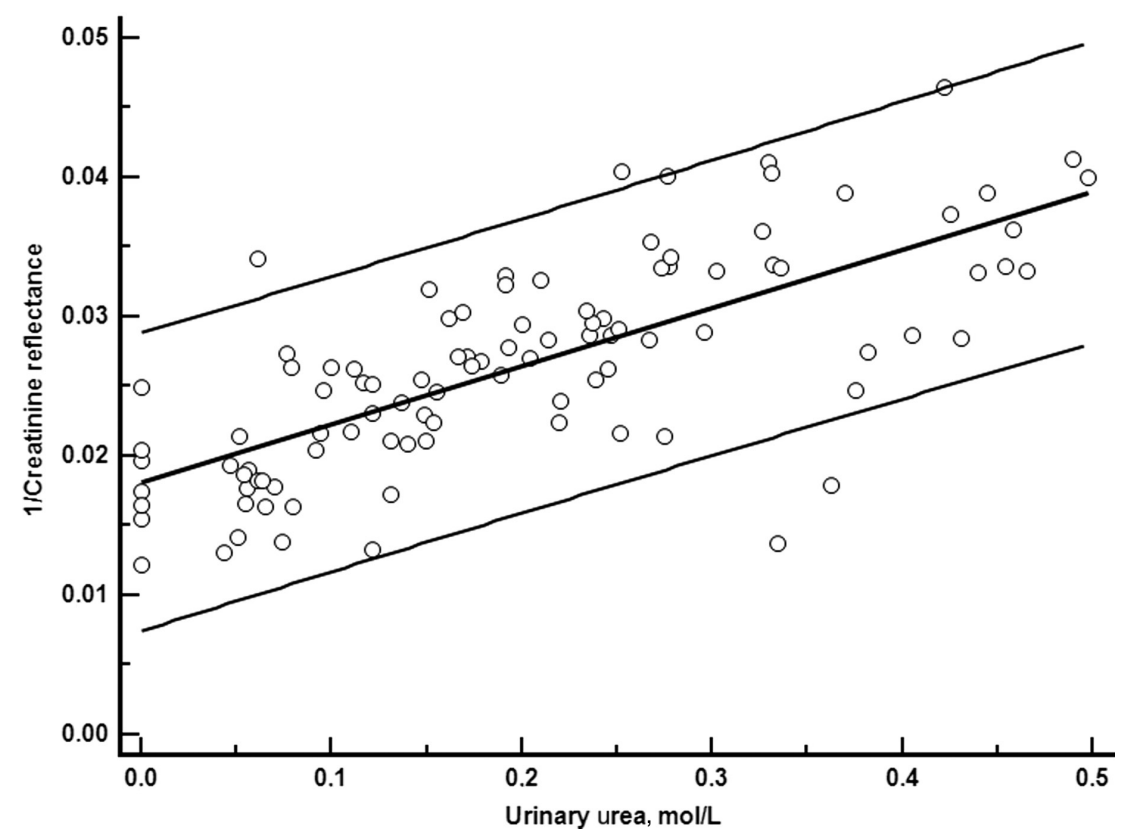

Figure 2: Correlation between the inverse reflectance data of the creatinine pad and the urinary urea concentration. $y(1 /$ reflectance creatinine $[\%])=0.04162$ (urea concentration, $\mathrm{mol} / \mathrm{L})+0.01819 ;(\mathrm{r}=0.721)$. 


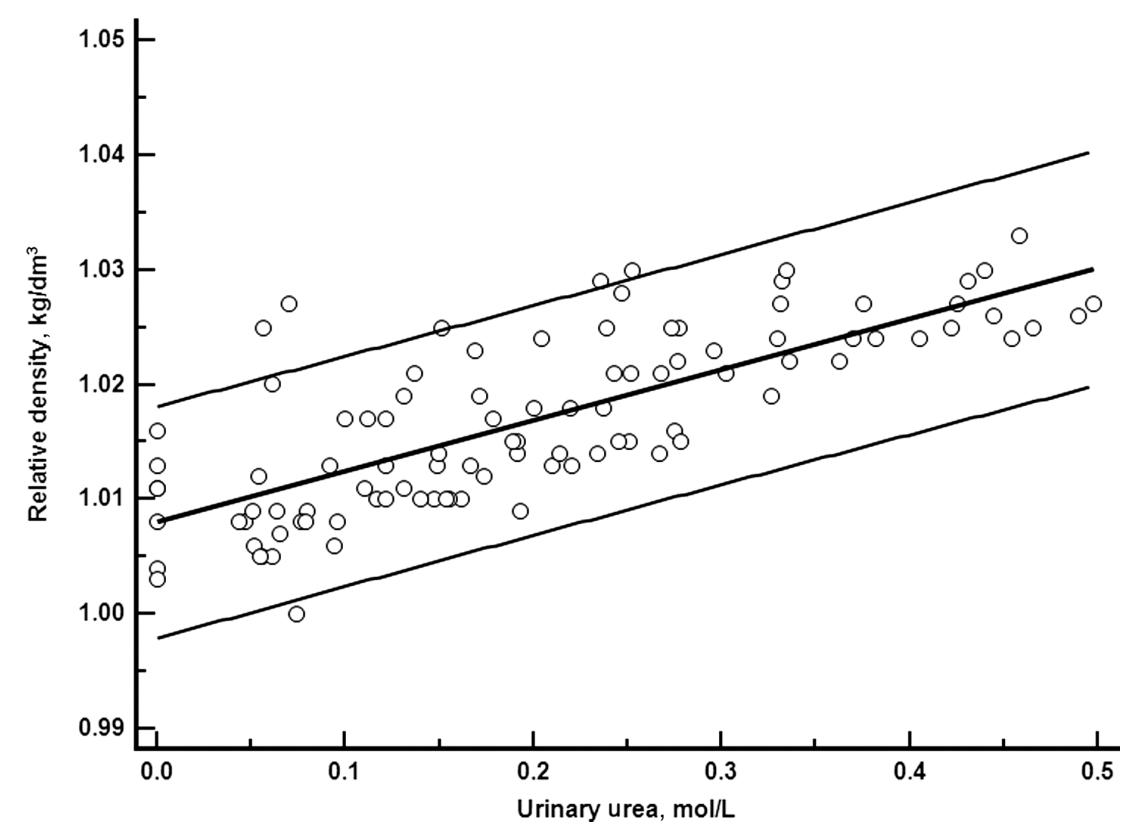

Figure 3: Correlation between the urinary relative density and urea concentration. $\mathrm{y}\left(\right.$ relative density, $\left.\mathrm{kg} / \mathrm{dm}^{3}\right)=0.04440 \times($ urea concentration, $\mathrm{mol} / \mathrm{L})+1.0080 ; \mathrm{r}=0.761$.

Similarly, the correlation between the urinary relative density and urea concentration was: $y$ (relative density, $\left.\mathrm{kg} / \mathrm{dm}^{3}\right)=0.04440 \times($ urea concentration, $\mathrm{mol} / \mathrm{L})+1.0080$; $\mathrm{r}=0.761$ (Figure 3 ).

Multiple linear mixed model analysis revealed that the strongest predictors of measured osmolality are electrical conductivity $(\beta=12.977$, standard error $[\mathrm{SE}]=1.219, \mathrm{p}<0.001)$, completed by creatinine $(\beta=7468.5$, $\mathrm{SE}=1262.2, \quad \mathrm{p}<0.001)$ and relative density $(\beta=14.954$, $\mathrm{SE}=1360.2, \mathrm{p}<0.001)$. The $\mathrm{r}^{2}$ value of the final model was 0.895 . Including only diabetic patients (urinary glucose $>0.28 \mathrm{mmol} / \mathrm{L}$ ) did not alter the parameters included in the model. The results of the multiple linear mixed model analysis of the separate groups are summarized in Table 2.

On the basis of these results, the measured osmolality can be predicted using the equation: predicted osmolality $=12.977 \times$ conductivity $+7468.5 \times 1 /$ creatinine reflectance $+14.954 \times$ relative density -15061 , were conductivity measured on the UF- 5000 is expressed in

Table 2: Overview of the prediction model parameters predicting measured urinary osmolality.

\begin{tabular}{lrrr}
\hline Variable & $\boldsymbol{\beta}^{\mathrm{a}}$ & $\mathrm{SE}$ & $\mathrm{p}$-Value \\
\hline Conductivity, $\mathrm{mS} / \mathrm{cm}$ & 12.98 & 1.22 & $<0.0001$ \\
1/creatinine reflectance & 7468.5 & 1262.2 & $<0.0001$ \\
Relative density & 14.954 & 1360.2 & $<0.0001$ \\
Coefficient & -15.061 & & \\
\hline
\end{tabular}

${ }^{a} \beta, \beta$-coefficient; SE, standard error.
$\mathrm{mS} / \mathrm{cm}$, creatinine reflectance measured on the UC-3500 is in $\%$ and relative density measured on the UC-3500 is in $\mathrm{kg} / \mathrm{dm}^{3}$.

\section{Validation of the osmolality prediction formulae}

Validation of the osmolality prediction model was evaluated using data from 36 patients. The medium osmolality was $546 \mathrm{mOsm} / \mathrm{kg}$ (range: $72-1028 \mathrm{mOsm} / \mathrm{kg}$ ). The predicted vs. measured plots for the patients included in the validation module are presented in Figure 4. The following regression equation was obtained: predicted osmolality $(\mathrm{mOsm} / \mathrm{kg})=1.026 \times$ (measured osmolality) 24.90; $\mathrm{r}^{2}=0.974$, and the mean difference was $1.33 \mathrm{mOsm} /$ $\mathrm{kg}(95 \%$ CI: -18.86 to $21.53 \mathrm{mOsm} / \mathrm{kg})$.

\section{Effect of glucose}

In urine specimens containing glucose (molecular mass: $180.16 \mathrm{~g} / \mathrm{mol}$ ), conductivity was unaffected by glucosuria. Hence, the estimated osmolality by the UF-5000 was insensitive to glucose, whereas the osmometer correctly responded to the glucose concentration (as measured chemically). The refractory index-based calculation of relative density correlated well with the measured osmolality: y (relative density, $\left.\mathrm{kg} / \mathrm{dm}^{3}\right)=0.0000457 \times$ (measured osmolality, $\mathrm{mOsm} / \mathrm{kg})+0.9992 ; \mathrm{r}^{2}=0.996$. In patients 

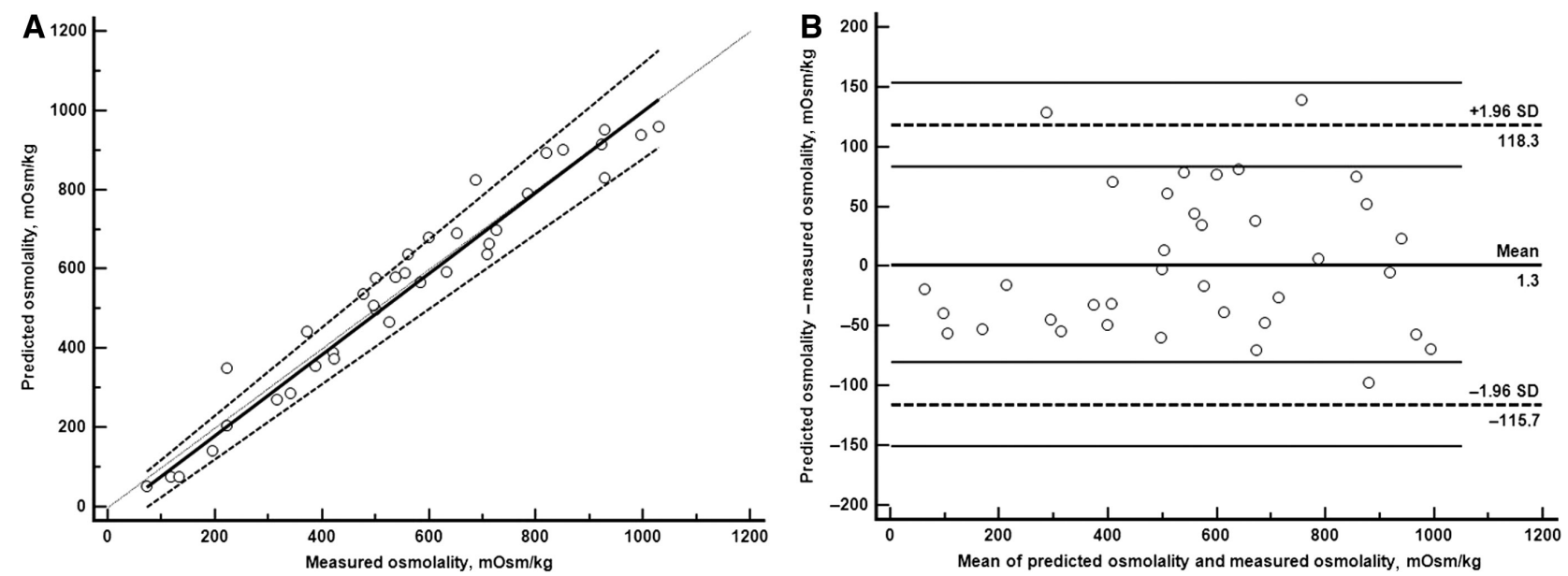

Figure 4: Validation of our osmolality prediction model.

(A) Regression analysis of the predicted osmolality and the measured osmolality in 36 samples. (B) Bland-Altman analysis of measured osmolality plotted against the predicted osmolality: predicted osmolality $(\mathrm{mOsm} / \mathrm{kg})=1.026 \times\left(\right.$ measured osmolality) $-24.90 ; r^{2}=0.974$. Horizontal lines are drawn at the mean difference $(\mathrm{mOsm} / \mathrm{kg})$ and the dashed lines represent the limit of agreement (LOA).

with pronounced glucosuria $(>0.83 \mathrm{mmol} / \mathrm{L})(\mathrm{n}=26)$, we observed an additional contribution of glucose to estimated urinary osmolality: y (measured osmolality, $\mathrm{mOsm} / \mathrm{kg})=20.47($ conductivity, $\mathrm{mS} / \mathrm{cm})+4397(1 /$ creatinine reflectance) +11.765 (relative density, $\left.\mathrm{kg} / \mathrm{dm}^{3}\right)+46.6$ glucose $(\mathrm{mmol} / \mathrm{L})\left(\mathrm{r}^{2}=0.918\right)$.

\section{Effect of contrast media}

As iodine contrast media are uncharged particles, spiking contrast media to pooled urine resulted in a reduction of conductivity and hence in a paradoxical reduction of the estimated osmolality by the UF-5000. In contrast, the osmometer detected the presence of the iomeprol particles according to predictions (Figure 5). In the concentration range from $0 \%$ to $30 \%$, refractometry-based relative density showed an excellent correlation with the concentration of contrast media: relative density $\left(\mathrm{kg} / \mathrm{dm}^{3}\right)=0.0014(\%$ contrast agent) $+1.000 ; \mathrm{r}^{2}=0.985 ; \mathrm{n}=21$.

The presence of contrast media in urine specimens can be assessed based on the conductivity/relative density ratio: y (estimated osmolality/relative density) $=764.1-$ $13.45 \times(\%$ contrast agent $), r^{2}=0.996 ; n=21$.
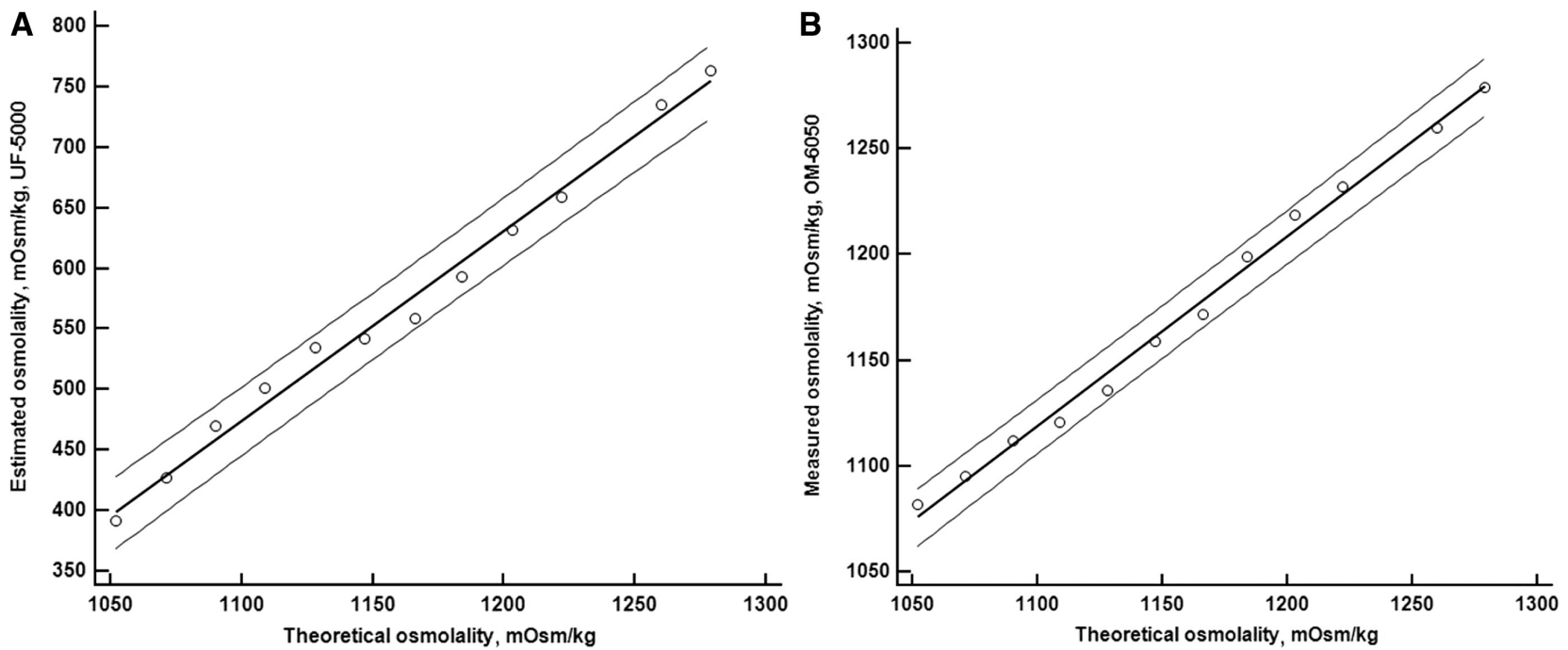

Figure 5: Estimated and measured osmolality vs. the theoretical value in mixtures of pooled urine and lopremol $300^{\circledR}$.

(A) y (estimated osmolality $[\mathrm{mOsm} / \mathrm{kg}])=1.58 \times$ (theoretical osmolality, $\mathrm{mOsm} / \mathrm{kg}$ ) $-1249.69, \mathrm{r}^{2}=0.990 ;$ (B) y (measured osmolality [mOsm/ $\mathrm{kg}])=0.896 \times($ theoretical osmolality, $\mathrm{mOsm} / \mathrm{kg})+133.70, \mathrm{r}^{2}=0.994$. 


\section{Discussion}

Our study presents interesting information on the estimation of urinary osmolality measured on a routine urine sediment analyzer. Compared to the freezing-point depression method, the UF-5000 analyzer showed excellent analytical performance results for both osmolality and conductivity. Conductivity-based estimation of osmolality (as carried out by the manufacturer) allows a rough estimation of the measured osmolality but fails to generate reliable results in case of the presence of uncharged particles (e.g. glucose, contrast media).

Urinary urea concentration (which reflects the daily protein intake) is an important variable source of error in the estimation of urinary osmolality. Urinary urea output reflects the amount of protein in the diet and shows an important inter-individual variation [18]. Urinary urea is a major contributor of osmolality. On average, urinary urea output is in the magnitude of $0.5 \mathrm{~mol} / 24 \mathrm{~h}$ [18], accounting for about half of urinary osmolality in non-diabetics. As urea values are not available on commercial test strips, these concentrations were not taken into account in the model. However, urinary urea concentration roughly correlates with urinary creatinine values measured on the UC-3500 urinary test strip reader. As the latter can be quantitatively measured on the urine strip, creatinine values can be used as a surrogate marker for urea. Also, relative density correlates with urea concentration. Unlike osmolality, which is only affected by the number of particles, refractometry is affected by the number, mass and chemical structure of the dissolved particles; hence large molecules like roentgen contrast media or mannitol will increase relative density relative to osmolality. The reagent strip is minimally affected by glucose, mannitol or radiographic contrast [18], but is largely affected by urinary $\mathrm{pH}$ such that only urine in the $\mathrm{pH}$ range of 7.0-7.5 can be correctly interpreted. The measurement of the relative density using a reagent strip is based on the ionic strength of the urine [19] and thus is significantly affected by the ionic composition of the urine and by proteins which have an electric charge in solution. In our experience, relative density measured by the refractometer is consistently more accurate than the reagent strip.

It is well known that the presence of contrast media in urine falsely increases relative density [7]. This effect is detected by refractometry but not by ionic strength-based urinary test strips $[19,20]$. The electrical conductivity is insensitive for the presence of iodine containing contrast media. Therefore, the presence of contrast agents in urine results in a falsely low conductivity-based estimated osmolality. The presence of roentgen contrast media in urine samples is very common among hospitalized patients during the first hours following contrast-enhanced radiography. We demonstrated that the concentration of roentgen contrast media can be estimated based on the estimated osmolality/relative density ratio.

Relative density as measured by refractometry is influenced by proteinuria, such that for each $10 \mathrm{~g} / \mathrm{L}$ protein the relative density increases by $0.003 \mathrm{~kg} / \mathrm{dm}^{3}$. Relative density is also affected by glucosuria such that it increases by approximately $0.002 \mathrm{~kg} / \mathrm{dm}^{3}$ per $10 \mathrm{~g} / \mathrm{L}(55 \mathrm{mmol} / \mathrm{L})$ glucose when compared with urinary osmolality. Similarly, $10 \mathrm{~g} / \mathrm{L}$ glucose corresponds with an increase in the refractory index of 0.00177 [21]. As relative density (measured by refractometry) is affected by glucose concentrations, osmolality estimations can be improved by adding glucosuria.

In diabetics, the performance of the calculated osmolality test is much weaker due to the presence of variable amounts of glucose in urine. However, the recent introduction of SGLT2 inhibitors in the treatment of diabetes [22] which induces a therapeutic glucosuria has increased the number of samples presenting with glucosuria. Also, urinary urea concentration (a reflection of protein intake) is an important variable source of error. Urinary urea output reflects the amount of protein in the diet.

For the clinician who is interpreting urine relative density results, it is important to be aware of these limitations and understand the reasons for possible potential errors of each particular method. Our findings allowed to develop a multiple linear mixed model analysis based on routine urinalysis data which revealed that the strongest predictors of estimated osmolality were conductivity, along with creatinine and relative density. Although modern osmometers allow a very good precision [23], the predictions provided by our model allowed an acceptable accuracy.

Next to its significance as a dilution parameter in urinalysis, estimating urinary osmolality might also be useful for improving the quality of analysis of dysmorphic RBCs [24]. Variation in osmotic pressure induces RBC volume changes and morphological alterations of $\mathrm{RBC}$ membranes. The morphology of RBCs using the Sysmex urinalysis instruments is assessed by two other pieces of information. Specifically, the comprehensive size of RBCs (RBC-P70 forward scatter) and the variety of Fsc of the RBCs (RBC-Fsc-distribution width) are used as standards for judgment. The input of urinary osmolality data into these algorithms might improve the assessment of dysmorphic RBCs in urinalysis.

In conclusion, we have evaluated the analytical performance of the parameters conductivity and estimated 
osmolality measured on the Sysmex UF-5000. We further developed an algorithm for estimating osmolality based on urinary creatinine, relative density and conductivity, determined on a routine urine test strip and urine sediment analyzer. We observed an excellent correlation with the concentration of contrast media to spiked urinary samples. Future studies need to establish whether this formula can be used to report osmolality in routine clinical practice.

Acknowledgments: We would like to thank the laboratory technicians from the core laboratory of the University Hospital Ghent for their very valuable efforts.

Author contributions: All the authors have accepted responsibility for the entire content of this submitted manuscript and approved submission.

Research funding: None declared.

Employment or leadership: None declared.

Honorarium: None declared.

Competing interests: The funding organization(s) played no role in the study design; in the collection, analysis, and interpretation of data; in the writing of the report; or in the decision to submit the report for publication.

\section{References}

1. Birch DF, Fairley KF. Haematuria: glomerular or non-glomerular? Lancet 1979;2:845-6.

2. Shirreffs SM, Maughan RJ. Urine osmolality and conductivity as indices of hydration status in athletes in the heat. Med Sci Sports Exerc 1998;30:1598-602.

3. McCrossin T, Roy LP. Comparison of hydrometry, refractometry, osmometry, and Ames N-Multistix SG in estimation of urinary concentration. Aust Paediatr J 1985;21:185-8.

4. Brandon CA. Urine specific gravity measurement: reagent strip versus refractometer. Clin Lab Sci 1994;7:308-10.

5. Dorizzi RM, Caputo M. Measurement of urine relative density using refractometer and reagent strips. Clin Chem Lab Med 1998;36:925-8.

6. Crespi V, Maio RC, Veronesi G, Gianfagna F, Taborelli S, Ferrario $M M$. Workplace drug testing on urine samples: evidence for improving efficacy of a first-level screening program. Med Lav 2015;106:374-85.

7. Giasson J, Chen Y. A discrepant urine specific gravity. Clin Chem 2012;58:797-802.
8. Adams LJ. Evaluation of Ames Multistix-SG for urine specific gravity versus refractometer specific gravity. Am J Clin Pathol 1983;80:871-3.

9. Langlois M, Delanghe J, Steyaert RS, Everaert KC, De Buyzere ML. Automated flow cytometry compared with an automated dipstick reader for urinalysis. Clin Chem 1999;45:118-22.

10. Baxmann AC, Ahmed MS, Marques NC, Menon VB, Pereira AB, Kirsztajn GM, et al. Influence of muscle mass and physical activity on serum and urinary creatinine and serum cystatin C. Clin J Am Soc Nephrol 2008;3:348-54.

11. Delanghe JR, Himpe J, Decock N, Delanghe S, De Herde K, Stove $\mathrm{V}$, et al. A sensitive quantitative test strip based point of care albuminuria assay. Clin Chim Acta 2017;471:107-12.

12. Delanghe J, Speeckaert M. Preanalytics in urinalysis. Clin Biochem 2016;49:1346-50.

13. Previtali G, Ravasio R, Seghezzit M, Buoro S, Alessio MG. Performance evaluation of the new fully automated urine particle analyser UF-50000 compared to the reference method of the Fuchs-Rosenthal chamber. Clin Chim Acta 2017;472:123-30.

14. Penders J, Fiers T, Delanghe J. Quantitative evaluation of urinalysis tests strips. Clin Chem 2002;48:2236-41.

15. Dooley M, Jarvis B. lomeprol: a review of its use as a contrast medium. Drugs 2000;59:1169-86.

16. Armbruster DA, Terry P. Limit of blank, limit of detection and limit of quantification. Clin Biochem Rev 2008;29:S49-52.

17. Speeckaert M, Delanghe J. Chapter 8. Tubular function. In: Turner N, Goldsmith D, Winearls C, Lameire N, Himmelfarb J, Remuzzi G, editors. Oxford textbook of clinical nephrology, 4th ed. Oxford: Oxford University Press, 2015:62-5.

18. Bingham SA, Williams R, Cole TJ, Price CP, Cummings JH. Reference values for analytes of 24-h urine collections known to be complete. Ann Clin Biochem 1988;25:610-9.

19. Chadha V, Garg U, Alon US. Measurement of urinary concentration: a critical appraisal of methodologies. Pediatr Nephrol 2001;16:374-82.

20. Feeney DA, Osborn CA, Jessen CR. Effects of radiographic contrast media on results of urinalysis, with emphasis on alteration in specific gravity. J Am Vet Med Assoc 1980;176:1378-81.

21. Lide DR, ed. CRC handbook of physics and chemistry, $82 \mathrm{nd}$ ed. Cleveland, OH: The Chemical Rubber Company, 2001.

22. Lupsa BC, Inzucchi SE. Use of SGLT2 inhibitors in type 2 diabetes: weighing the risks and benefits. Diabetologia 2018;61:2118-25.

23. Guerrero S, Pastor J, Tvarijonaviciute A, Cerón JJ, Balestra G, Caldin M. Analytical validation and reference intervals for freezing point depression osmometer measurements of urine osmolality in dogs. J Vet Diagn Invest 2017;29:791-6.

24. Schramek P, Moritsch A, Haschkowitz H, Binder BR, Maier M. In vitro generation of dysmorphic erythrocytes. Kidney Int 1989;36:72-7. 